\title{
Gilteritinib: a novel FLT3 inhibitor for acute myeloid leukemia
}

\author{
Juanjuan Zhao ${ }^{1}$, Yongping Song ${ }^{1 *}$ and Delong Liu ${ }^{1,2^{*}}$ (D)
}

\begin{abstract}
FMS-like tyrosine kinase 3- internal tandem duplication (FLT3-ITD) remains as one of the most frequently mutated genes in acute myeloid leukemia (AML), especially in those with normal cytogenetics. The FLT3-ITD and FLT3-TKD (tyrosine kinase domain) mutations are biomarkers for high risk AML and are associated with drug resistance and high risk of relapse. Multiple FLT3 inhibitors are in clinical development, including lestaurtinib, tandutinib, quizartinib, midostaurin, gilteritinib, and crenolanib. Midostaurin and gilteritinib have been approved by FDA for Flt3 mutated AML. Gilteritinib (ASP2215, Xospata) is a small molecule dual inhibitor of FLT3/AXL. The ADMIRAL study showed that longer overall survival and higher response rate are associated with gilteritinib in comparison with salvage chemotherapy for relapse /refractory (R/R) AML. These data from the ADMIRAL study may lead to the therapy paradigm shift and establish gilteritinib as the new standard therapy for R/R FLT3-mutated AML. Currently, multiple clinical trials are ongoing to evaluate the combination of gilteritinib with other agents and regimens. This study summarized clinical trials of gilteritinib for AML.
\end{abstract}

Keywords: FLT3, Gilteritinib, Tyrosine kinase inhibitor, FLT3 inhibitor

\section{Background}

Recurrent and novel genetic mutations are increasingly discovered through FISH, PCR and next-generation sequencing studies of leukemia specimens [1-5]. These findings led to new classifications of leukemia $[2,6]$. New agents targeting these recurrent mutations are rapidly emerging for high-risk acute myeloid leukemia (AML) [7, 8]. Among these common mutations, FMS-like tyrosine kinase 3-internal tandem duplication (FLT3-ITD) remains as one of the most frequently mutated genes in AML, especially in those with normal cytogenetics, in which the mutation rate can be as high as $30 \%$ [9-11].

FLT3 gene encodes a receptor type tyrosine kinase which plays a key role in the proliferation, differentiation, and survival of hematopoietic stem cells. FLT3ITD leads to constitutive activation of the FLT3 tyrosine kinase, resulting in uncontrolled cell proliferation and high WBC counts in AML patients [12, 13].

The FLT3-ITD and FLT3-TKD (tyrosine kinase domain) mutations are biomarkers for high risk AML

\footnotetext{
*Correspondence: songyongping@163.com; DELONG_LIU@NYMC.EDU

${ }^{1}$ Department of Oncology, The first Affiliated Hospital of Zhengzhou

University, Zhengzhou 450052, China

Full list of author information is available at the end of the article
}

and are associated with drug resistance and high risk of relapse $[14,15]$, particularly in those patients with wildtype NPM1 and high alleilic ratio of FLT3-ITD. These mutations can also serve as biomarkers for minimal residual diseases [16]. Allogeneic hematopoietic stem cell transplantation (HSCT) is routinely recommended for AML patients with high alleilic ratio of FLT3/ITD and TKD mutations [17]. Oral tyrosine kinase inhibitors (TKI) are widely used for targeted therapy of chronic myeloid leukemia and myeloproliferative neoplasms [18-21]. FLT3/ITD and FLT3/TKD are ideal targets for small molecule inhibitors. Multiple FLT3 inhibitors are in clinical development, including sorafenib, lestaurtinib, sunitinib, tandutinib, quizartinib, midostaurin, gilteritinib, crenolanib, cabozantinib, Sel24-B489, G-749, AMG 925, TTT-3002, and FF-10101 [22-30]. Midostaurin and gilteritinib have been approved by FDA for Flt3 mutated AML [31]. This study summarized clinical trials of gilteritinib for AML.

\section{Gilteritinib (ASP2215, Xospata) for relapsed and /or refractory AML (R/R AML)}

Gilteritinib is a small molecule dual inhibitor of FLT3/ AXL. In a phase I/II study in relapsed /refractory (R/R) 
AML with or without FLT3 mutations, gilteritinib was given as once-daily doses in dose-escalation and doseexpansion cohorts $(20 \mathrm{mg}, 40 \mathrm{mg}, 80 \mathrm{mg}, 120 \mathrm{mg}, 200$ $\mathrm{mg}, 300 \mathrm{mg}$, or $450 \mathrm{mg}$ ) (Table 1, NCT02014558). In the expansion cohort, doses at $120 \mathrm{mg}$ and $200 \mathrm{mg}$ were given to those R/R AML with FLT3 mutations. In the published report, 23 patients were enrolled in the doseescalation cohort, 229 patients were included in the dose-expansion cohort [32]. The dose-limiting toxicities (DLT) were grade 3 diarrhea and elevated aspartate aminotransferase (ALT) at the daily dose of $450 \mathrm{mg}$. Therefore $300 \mathrm{mg} /$ day was the maximum tolerated dose (MTD). The most common treatment-emergent adverse events (TEAE) were diarrhea, anemia, fatigue, and liver enzyme elevation. In the group of 249 patients for full analysis, overall response rate (ORR) was $40 \%$. In summary, gilteritinib was well tolerated in patients with R/R AML. This trial established the daily dose of $120 \mathrm{mg}$ gilteritinib for further clinical phase 3 trials.
Gilteritinib was studied in another phase 1 study in Japanese patients with R/R AML (table, NCT02181660). Gilteritinib was given as daily escalating doses in 6 cohorts, with doses ranging from $20,40,80,120,200$, to $300 \mathrm{mg} /$ day. In the published report, 24 subjects were enrolled [33]. Grade 3 tumor lysis syndrome (TLS) was observed at the dose $120 \mathrm{mg} /$ day in one patient. At 300 $\mathrm{mg} /$ day, two patients developed grade 3 elevated lactate dehydrogenase (LDH), amylase, creatine phosphokinase levels, and syncope. These grade 3 toxicities were DLTs. The MTD was established at $200 \mathrm{mg} /$ day. Among the 5 patients with FLT3 mutations, the ORR was $80 \%(n=4)$. Four of 11 patients with wild-type FLT3 also responded. This study also established the $120 \mathrm{mg}$ once-daily as the recommended dose in the Japanese patients.

Gilteritinib was compared with salvage chemotherapy in R/R AML with mutated FLT3 in an open-label, multicenter, randomized phase III study (ADMIRAL study; NCT03182244) [34]. Gilteritinib was given at $120 \mathrm{mg}$

Table 1 Clinical trials of gilteritinib for acute myeloid leukemia

\begin{tabular}{|c|c|c|c|c|c|}
\hline No. & AML status & therapy & Phase & NCT & Trial Status \\
\hline 1 & R/R AML & Gilteritinib & Phase 1 & 02181660 & Completed \\
\hline 2 & $\mathrm{R} / \mathrm{R}$ AML & Gilteritinib & Phase $1 / 2$ & 02014558 & Completed \\
\hline 3 & Previously Untreated AML with FLT3 Mutation & Gilteritinib & Phase $1 / 2$ & 03013998 & Recruiting \\
\hline 4 & Advanced Solid Tumors and AML & Gilteritinib & Phase 1/2 & 02561455 & Enrolling by invitation \\
\hline 5 & $\begin{array}{l}\text { R/R AML with FLT3 Mutation or AML with FLT3 } \\
\text { Mutation in CR with MRD }\end{array}$ & Gilteritinib & NA & 03070093 & Available \\
\hline 6 & $\begin{array}{l}\text { R/R AML with FLT3 Mutation or AML with FLT3 } \\
\text { Mutation in CR with MRD }\end{array}$ & Gilteritinib & NA & 03409081 & No longer available \\
\hline 7 & $\begin{array}{l}\text { Pediatric R/R AML with FLT3 Mutation or AML } \\
\text { with FLT3 Mutation in CR with MRD }\end{array}$ & Gilteritinib & NA & 03315299 & No longer available \\
\hline 8 & $\mathrm{R} / \mathrm{R}$ AML & Gilteritinib + Venetoclax & Phase 1 & 03625505 & Recruiting \\
\hline 9 & Newly Diagnosed AML & $\begin{array}{l}\text { Gilteritinib + Cytarabine } \\
+ \text { Idarubicin }\end{array}$ & Phase 1 & 02310321 & Active, not recruiting \\
\hline 10 & Newly Diagnosed AML & $\begin{array}{l}\text { Gilteritinib + Cytarabine } \\
+ \text { Idarubicin or Gilteritinib } \\
\text { + Cytarabine + Daunorubicin }\end{array}$ & Phase 1 & 02236013 & Recruiting \\
\hline 11 & R/R AML with FLT3 Mutation & Gilteritinib + Atezolizumab & Phase 1/2 & 03730012 & Recruiting \\
\hline 12 & AML with FLT3/ITD Mutation in CR1 & Gilteritinib vs Placebo & Phase 2 & 02927262 & Active, not recruiting \\
\hline 13 & Untreated AML with FLT3 Mutation & $\begin{array}{l}\text { Gilteritinib + Daunorubicin } \\
+ \text { Cytarabine } \\
\text { vs Midostaurin + Daunorubicin } \\
+ \text { Cytarabine }\end{array}$ & Phase 2 & 03836209 & Not yet recruiting \\
\hline 14 & Newly Diagnosed AML With FLT3 Mutation & $\begin{array}{l}\text { Gilteritinib vs Gilteritinib + Azacitidine } \\
\text { vs Azacitidine }\end{array}$ & Phase $2 / 3$ & 02752035 & Recruiting \\
\hline 15 & $\begin{array}{l}\text { AML With FLT3/ITD Mutation in CR1 } \\
\text { undergoing allo-HSCT }\end{array}$ & Gilteritinib vs Placebo & Phase 3 & 02997202 & Recruiting \\
\hline 16 & R/R AML with FLT3 Mutation & Gilteritinib vs Salvage Chemotherapy & Phase 3 & 03182244 & Recruiting \\
\hline 17 & R/R AML with FLT3 Mutation & Gilteritinib vs Salvage Chemotherapy & Phase 3 & 02421939 & Active, not recruiting \\
\hline 18 & $\begin{array}{l}\text { Newly Diagnosed AML or MDS-EB2 } \\
\text { with FLT3 mutation }\end{array}$ & $\begin{array}{l}\text { Gilteritinib vs Midostaurin in Combination } \\
\text { With chemotherapy }\end{array}$ & Phase 3 & 04027309 & Not yet recruiting \\
\hline
\end{tabular}

Abbreviations: $R / R$, Relapsed or Refractory; FLT3, FMS-like Tyrosine Kinase 3; ITD, Internal Tandem Duplication; $C R$, Complete Remission; MRD, Minimal Residual Disease; MDS-EB2, Myelodysplastic Syndromes with Excess Blasts-2; NA, Not Available; allo-HSCT, allogeneic Hematopoietic Stem Cell Transplant 
daily, and randomized as 2:1 with one of the four salvage chemotherapy regimens (low-dose cytarabine, azacitidine, MEC, or FLAG-IDA) (Fig. 1). The primary endpoints were $\mathrm{OS}$ and $\mathrm{CR} / \mathrm{CRh}$ (complete remission with partial hematologic recovery). The accrual has been completed with 371 patients randomized.

In the pre-planned interim analysis of 138 patients enrolled in the gilteritinib group, CR/CRh was $21 \%$ (95\% CI $14.5-28.8, n=29 / 138)$, with $11.6 \%$ CR and 9.4\% CRh. The median duration of remission (DOR) was 4.6 months (range 0.1-15.8). The median time to response was 3.6 months (range 0.9-9.6). Based on these data, gilteritinib was approved by US FDA for R/R AML patients [35].

Among the 371 patients, 247 were randomized to gilteritinib and 124 to salvage chemotherapy [34]. The median age of the 371 patients was 62 years (range 19-85). Among the FLT3 mutations, 88.4\% were FLT3-ITD, 8.4\% were FLT3-TKD, and 1.9\% were both FLT3-ITD and FLT3-TKD, 1.3\% had unconfirmed mutations. The OS was significantly longer in the gilteritinib group (9.3 months) than that in the SC group (5.6 months) (hazard ratio $[\mathrm{HR}]$ for death $=0.637 ; P=0.0007$ ). The rates of $\mathrm{OS}$ at 1 year were $37.1 \%$ for gilteritinib group and $16.7 \%$ for the SC group. In the full analysis of the 371 patients randomized, the CR/CRh rate for gilteritinib group (34\%) was significantly better than that in the SC group $(15.3 \%, P=$ 0.0001). Cytopenia were the common serious adverse events (SAE) related to gilteritinib, including anemia, febrile neutropenia, and thrombocytopenia. Other clinically significant AEs that were observed in the clinical trials of gilteritinib included prolonged cardiac ventricular repolarization (QT interval, QTc, 9\%), pancreatitis (5\%), posterior reversible encephalopathy syndrome (1\%), and differentiation syndrome (3\%). Dexamethasone $10 \mathrm{mg}$ IV every $12 \mathrm{~h}$ (or an equivalent dose of an alternative oral or IV corticosteroid) should be initiated once differentiation syndrome is suspected. Careful hemodynamic monitoring should be done until clinical improvement. Steroids should be administered for a minimum of 3 days and can be tapered once the symptoms resolve.

In conclusion, gilteritinib as a single oral agent at 120 mg daily led to significantly longer OS and higher ORR than salvage chemotherapy. The overall safety profile also favors gilteritinib. These data from the ADMIRAL study may lead to the therapy paradigm shift and establish gilteritinib as the new standard therapy for $R / R$ FLT3-mutated AML.

\section{Gilteritinib in combination regimens}

The role of gilteritinib in combination regimens remains unclear. It is possible that adding gilteritinib to the commonly used chemotherapy agents and regimens may improve clinical efficacies. Currently, multiple clinical trials are ongoing to evaluate the combination of gilteritinib with other agents and regimens (Table 1).

Epigenetic dysregulation plays a major role in leukemogenesis [36-39]. Hypomethylating agents have been shown to be active in AML as a single agent as well as in combination regimens [40-46]. A multicenter, openlabel, 3-arm study is being done to compare gilteritinib, gilteritinib plus azacitidine (AZA), or azacitidine alone in newly diagnosed FLT3 mutated (FLT3 mut+) AML patients who are unfit for intensive induction chemotherapy (NCT02752035). To evaluate the appropriate gilteritinib

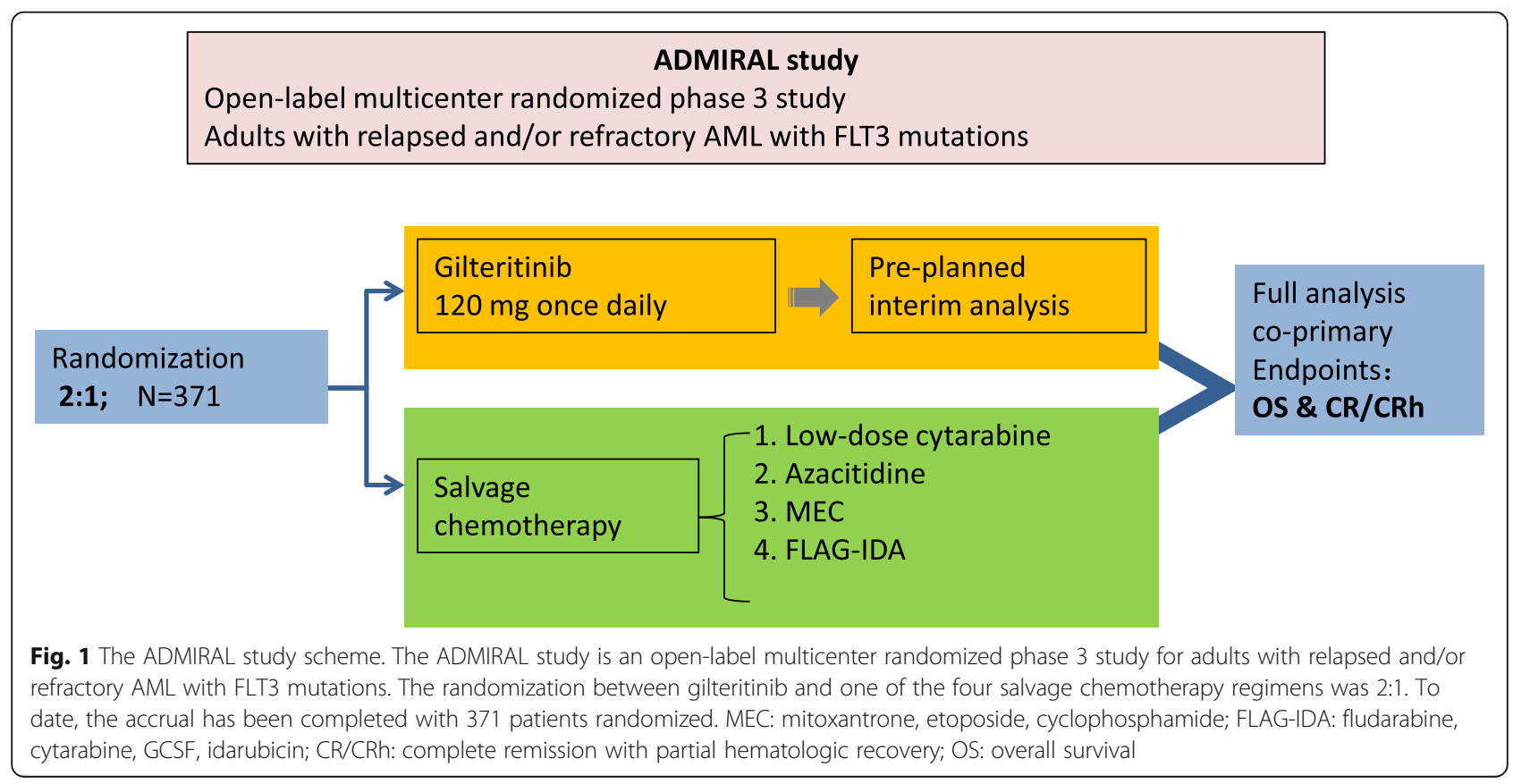


dose for combination therapy prior to the 3-arm randomized phase, patients were enrolled in a safety cohort who received gilteritinib either $80 \mathrm{mg}$ or $120 \mathrm{mg} /$ day with AZA at $75 \mathrm{mg} / \mathrm{m} 2$ on days $1-7$. Each treatment cycle is 28 days. In a recent update at the $2018 \mathrm{ASH}$ annual meeting, 15 adult patients were recruited to the safety cohort [47]. Among these patients with a median age of 76 (range 6586), 9 received gilteritinib at $80 \mathrm{mg}$, and 6 at $120 \mathrm{mg}$ daily. One patient who received $80 \mathrm{mg}$ gilteritinib plus AZA developed TLS as the DLT, whereas no DLTs were observed in patients who had $120 \mathrm{mg}$ gilteritinib plus AZA. Cytopenia were the common SAEs. Eight patients had fatal events that were not related to therapy. The ORR was $80 \%$, and composite CR was $67 \%(n=10 / 15)$. In conclusion, the combination of gilteritinib with AZA was well tolerated. These data from the safety cohort led to the decision to use a dose of $120 \mathrm{mg}$ gilteritinib plus AZA in the randomized portion of the 3-arm study. The preliminary data showed antileukemic responses in these newly diagnosed FLT3mut + elderly unfit AML patients. This trial could provide evidence for a new regimen for elderly AML patients [48].

In an ongoing open-label, dose-escalation /expansion phase 1 study, gilteritinib is being studied in combination with front-line $7+3$ induction chemotherapy in adult patients with newly diagnosed AML (NCT02236013). This study also includes consolidation phase with high-dose cytarabine, and maintenance therapy with single-agent gilteritinib. Dose escalation of gilteritinib was planned at 40 , 80,120 , or $200 \mathrm{mg} /$ day. During the initial 2 cycles of a standard $7+3$ induction regimen (cytarabine plus idarubicin [dose-escalation and dose-expansion cohorts], gilteritinib was given on days 4-17 [Schedule 1]). Once the doseexpansion cohort using Schedule 1 was completed, a new cohort of six patients were enrolled, with gilteritinib given on days 8-21 (Schedule 2). For the consolidation phase, cytarabine was planned at $1.5 \mathrm{~g} / \mathrm{m} 2$ every $12 \mathrm{~h}$ on days 1,3 , and 5 together with gilteritinib on days $1-14$. For responding subjects with appropriate donors, HSCT was allowed. For the maintenance phase after consolidation or transplantation, gilteritinib was given daily as a single agent for $\leq 26$ cycles. In the update at the 2018 ASH annual meeting, 62 patients were enrolled, with 60 eligible for safety analysis [49]. Among these patients, FLT3 mutations were seen in $53.3 \%$. DLTs with neutropenia, thrombocytopenia, and decreased ejection fraction were observed during the dose escalation at the dose $40 \mathrm{mg} /$ day of gilteritinib. To reduce toxicities, the gilteritinib induction schedule was modified. After this adjustment, two patients reported DLTs with neutropenia and neutropenic enterocolitis in the $200 \mathrm{mg} /$ day cohort. The MTD was established at $120 \mathrm{mg} /$ day which was also recommended as the expansion dose. For FLT3mut + patients receiving gilteritinib $120 \mathrm{mg}$ on Schedule 1 , all 17 patients who were evaluable for efficacy achieved 100\% composite CR (CRc). Interestingly, those patients receiving Schedule 2 induction with daunorubicin also had $100 \%$ CRc rate. Enrollment in the Schedule 2 cohort receiving idarubicin is ongoing; the two subjects in this cohort have not been assessed for response. Among 47 patients who received $\geq 80 \mathrm{mg} /$ day gilteritinib, the CRc rate for those patients with FLT3 mutations reached $88.9 \%$ ( $n=$ 24/27). In conclusion, gilteritinib in combination with intensive chemotherapy for induction was well tolerated. Two different gilteritinib schedules in combination with idarubicin or daunorubicin induced high ORR in those patients with FLT3 mutations. Overall survival and long-term outcome are still being monitored.

Midostaurin has been approved for combination with induction chemotherapy for newly diagnosed AML patients with FLT3 mutations [30, 31, 50, 51]. A phase 3 randomized study has been planned to compare gilteritinib with midostaurin in combination with induction chemotherapy (NCT04027309, Table 1). Gilteritinib is also being studied in combination with venetoclax as a chemotherapy-free regimen for R/R AML (NCT03625505). More studies are being planned or ongoing for AML with FLT3 mutations (Table 1).

\section{Future perspectives}

Among the FLT3 inhibitors in clinical trials, crenolanib is in multiple trials for $\mathrm{R} / \mathrm{R}$ AML as well as for frontline regimens for newly diagnosed AML $[22,52,53]$. Patients who were resistant to gilteritinib and other FLT3 inhibitors were also being included in some studies of crenolanib $[53,54]$. It is forseeable that more FLT3 inhibitors may become available for clinical applications [55-58]. It will be possible to choose among the approved agents according to a unique property for a particular patient in the near future. At this time, gilteritinib is the only approved FLT3 inhibitor as a single agent for R/R AML with FLT3 mutations, as suggested in the NCCN guidelines $[59,60]$.

Sorafenib, midostaurin as well as gilteritinib are being studied as maintenance therapy after HSCT for AML with FLT3 mutations $[7,10,56]$. FLT3 inhibitors including gilteritinib may have the potential for AML maintenance therapy, though definitive data from clinical trials are not available yet (Table 1).

\section{Conclusion}

Gilteritinib has been approved for R/R AML with FLT3 mutations. The ADMIRAL study showed that longer overall survival and higher response rate are associated with gilteritinib in comparison with salvage chemotherapy for R/R AML. These data from the ADMIRAL study may lead to the therapy paradigm shift and establish gilteritinib as the new standard therapy for R/R FLT3mutated AML. 


\section{Abbreviations}

CR: Complete remission; CR/CRh: Complete remission with partial hematologic recovery; GCSF: Idarubicin; MEC: Mitoxantrone, etoposide, cyclophosphamideFLAG-IDAFludarabine, cytarabine; MRD: Minimal residual disease; ORR: Overall response rate; OS: Overall survival; PFS: Progression free survival

\section{Acknowledgements}

DL is a Professor of Medicine at the New York Medical College and Westchester Medical Center, Valhalla, NY 10595, USA.

\section{Competing interests}

$\mathrm{DL}$ serves on the Xospata speaker bureau of Astellas. Astellas was not involved in this publication.

\section{Authors' contributions}

$\mathrm{DL}$ designed the study and drafted the manuscript. DL and JZ prepared the table and figure. All authors participated in the revision of the manuscript. All authors read and approved the final manuscript.

\section{Funding}

The study is partly supported by the Affiliated First Hospital of Zhengzhou University, Zhengzhou, China.

\section{Availability of data and materials}

The material supporting the conclusion of this review has been included within the article.

\section{Ethics approval and consent to participate}

This is not applicable for this review.

\section{Consent for publication}

This is not applicable for this review.

\section{Author details}

'Department of Oncology, The first Affiliated Hospital of Zhengzhou University, Zhengzhou 450052, China. ${ }^{2}$ Division of Hematology \& Oncology, New York Medical College, Valhalla, NY 10595, USA.

\section{Received: 22 July 2019 Accepted: 21 August 2019}

\section{Published online: 11 September 2019}

\section{References}

1. Bejar R, Stevenson K, Abdel-Wahab O, Galili N, Nilsson B, Garcia-Manero G, Kantarjian H, Raza A, Levine RL, Neuberg D, Ebert BL. Clinical effect of point mutations in myelodysplastic syndromes. N Engl J Med. 2011; 364(26):2496-506

2. Papaemmanuil E, Gerstung M, Bullinger L, Gaidzik VI, Paschka P, Roberts ND, Potter NE, Heuser M, Thol F, Bolli N, Gundem G, Van Loo P, Martincorena I, Ganly P, Mudie L, McLaren S, O'Meara S, Raine K, Jones DR, Teaque JW, Butler AP, Greaves MF, Ganser A, Döhner K, Schlenk RF, Döhner H, Campbell PJ. Genomic classification and prognosis in acute myeloid leukemia. N Engl J Med. 2016;374(23):2209-21.

3. Patel JP, Gönen M, Figueroa ME, Fernandez H, Sun Z, Racevskis J, Van Vlierberghe P, Dolgalev I, Thomas S, Aminova O, Huberman K, Cheng J, Viale A, Socci ND, Heguy A, Cherry A, Vance G, Higgins RR, Ketterling RP, Gallagher RE, Litzow M, van den Brink MRM, Lazarus HM, Rowe JM, Luger S, Ferrando A, Paietta E, Tallman MS, Melnick A, Abdel-Wahab O, et al. Prognostic relevance of integrated genetic profiling in acute myeloid leukemia. N Engl J Med. 2012;366(12):1079-89.

4. Wei H, Wang Y, Zhou C, Lin D, Liu B, Liu K, Qiu S, Gong B, Li Y, Zhang G, Wei S, Gong X, Liu Y, Zhao X, Gu R, Mi Y, Wang J. Distinct genetic alteration profiles of acute myeloid leukemia between Caucasian and eastern Asian population. J Hematol Oncol. 2018;11(1):18.

5. Yang J. SALL4 as a transcriptional and epigenetic regulator in normal and leukemic hematopoiesis. Biomarker Res. 2018;6(1):1.

6. Boddu PC, Kadia TM, Garcia-Manero G, Cortes J, Alfayez M, Borthakur G, Konopleva M, Jabbour EJ, Daver NG, DiNardo CD, Naqvi K, Yilmaz M, Short NJ, Pierce S, Kantarjian HM, Ravandi F. Validation of the 2017 European LeukemiaNet classification for acute myeloid leukemia with NPM1 and FLT3-internal tandem duplication genotypes. Cancer. 2019;125(7):1091-100.
7. Saygin C, Carraway HE. Emerging therapies for acute myeloid leukemia. J Hematol Oncol. 2017;10(1):93.

8. Yang X, Wang J. Precision therapy for acute myeloid leukemia. J Hematol Oncol. 2018;11(1):3.

9. Gu R, Yang X, Wei H. Molecular landscape and targeted therapy of acute myeloid leukemia. Biomarker Res. 2018:6(1):32.

10. Wu M, Li C, Zhu X. FLT3 inhibitors in acute myeloid leukemia. J Hematol Oncol. 2018;11(1):133.

11. Deeb KK, Smonskey MT, DeFedericis H, Deeb G, Sait SN, Wetzler M, Wang ES, Starostik P. Deletion and deletion/insertion mutations in the juxtamembrane domain of the FLT3 gene in adult acute myeloid leukemia. Leuk Res Rep. 2014;3(2):86-9.

12. Mizuki M, Fenski R, Halfter H, Matsumura I, Schmidt R, Muller C, Gruning W, Kratz-Albers K, Serve S, Steur C, Buchner T, Kienast J, Kanakura Y, Berdel WE, Serve $\mathrm{H}$. Flt3 mutations from patients with acute myeloid leukemia induce transformation of 32D cells mediated by the Ras and STAT5 pathways. Blood. 2000:96(12):3907-14.

13. Nguyen B, Williams AB, Young DJ, Ma H, Li L, Levis M, Brown P, Small D. FLT3 activating mutations display differential sensitivity to multiple tyrosine kinase inhibitors. Oncotarget. 2017;8(7):10931-44.

14. Wang ES, Sait SN, Gold D, Mashtare T, Starostik P, Ford LA, Wetzler M, Nowak NJ, Deeb G. Genomic, immunophenotypic, and NPM1/FLT3 mutational studies on 17 patients with normal karyotype acute myeloid leukemia (AML) followed by aberrant karyotype AML at relapse. Cancer Genet Cytogenet. 2010;202(2):101-7.

15. Thol F, Schlenk RF, Heuser M, Ganser A. How I treat refractory and early relapsed acute myeloid leukemia. Blood. 2015;126(3):319-27.

16. Yalniz F, Abou Dalle I, Kantarjian H, Borthakur G, Kadia T, Patel K, Loghavi S, Garcia-Manero G, Sasaki K, Daver N, DiNardo C, Pemmaraju N, Short NJ, Yilmaz M, Bose P, Naqvi K, Pierce S, Nogueras Gonzalez GM, Konopleva M, Andreeff M, Cortes J, Ravandi F. Prognostic significance of baseline FLT3-ITD mutant allele level in acute myeloid leukemia treated with intensive chemotherapy with/without sorafenib. Am J Hematol. 2019;94(9). https:// doi.org/10.1002/ajh.25553.

17. Rowe JM, Tallman MS. How I treat acute myeloid leukemia. Blood. 2010; 116(17):3147-56.

18. Cortes JE, Apperley JF, DeAngelo DJ, Deininger MW, Kota VK, Rousselot P, Gambacorti-Passerini C. Management of adverse events associated with bosutinib treatment of chronic-phase chronic myeloid leukemia: expert panel review. J Hematol Oncol. 2018;11(1):143.

19. Kvasnicka HM, Thiele J, Bueso-Ramos CE, Sun W, Cortes J, Kantarjian HM, Verstovsek S. Long-term effects of ruxolitinib versus best available therapy on bone marrow fibrosis in patients with myelofibrosis. J Hematol Oncol. 2018;11(1):42.

20. Ling Y, Xie $Q$, Zhang Z, Zhang H. Protein kinase inhibitors for acute leukemia. Biomarker Res. 2018;6(1):8.

21. Rossari F, Minutolo F, Orciuolo E. Past, present, and future of Bcr-Ab inhibitors: from chemical development to clinical efficacy. J Hematol Oncol. 2018;11(1):84

22. Wang ES, Tallman MS, Stone RM, Walter RB, Karanes C, Jain V, Collins RH. Low relapse rate in younger patients $\leq 60$ years old with newly diagnosed FLT3-mutated acute myeloid leukemia (AML) treated with Crenolanib and Cytarabine/anthracycline chemotherapy. Blood. 2017:130(Suppl 1):566.

23. Xuan $L$, Wang $Y$, Huang F, Jiang E, Deng L, Wu B, Fan Z, Liang X, Xu N, Ye J, Lin R, Yin C, Zhang Y, Sun J, Han M, Huang X, Liu Q. Effect of sorafenib on the outcomes of patients with FLT3-ITD acute myeloid leukemia undergoing allogeneic hematopoietic stem cell transplantation. Cancer. 2018;124(9):1954-63

24. Yamaura T, Nakatani T, Uda K, Ogura H, Shin W, Kurokawa N, Saito K, Fujikawa N, Date T, Takasaki M, Terada D, Hirai A, Akashi A, Chen F, Adachi Y, Ishikawa Y, Hayakawa F, Hagiwara S, Naoe T, Kiyoi H. A novel irreversible FLT3 inhibitor, FF-10101, shows excellent efficacy against AML cells with FLT3 mutations. Blood. 2018;131(4):426-38.

25. Lu JW, Wang AN, Liao HA, Chen CY, Hou HA, Hu CY, Tien HF, Ou DL, Lin LI. Cabozantinib is selectively cytotoxic in acute myeloid leukemia cells with FLT3internal tandem duplication (FLT3-TDD). Cancer Lett. 2016;376(2):218-25.

26. O'Farrell AM, Abrams TJ, Yuen HA, Ngai TJ, Louie SG, Yee KW, Wong LM, Hong W, Lee LB, Town A, Smolich BD, Manning WC, Murray LJ, Heinrich MC, Cherrington JM. SU11248 is a novel FLT3 tyrosine kinase inhibitor with potent activity in vitro and in vivo. Blood. 2003:101(9): 3597-605. 
27. Sandmaier BM, Khaled S, Oran B, Gammon G, Trone D, Frankfurt O. Results of a phase 1 study of quizartinib as maintenance therapy in subjects with acute myeloid leukemia in remission following allogeneic hematopoietic stem cell transplant. Am J Hematol. 2018;93(2):222-31.

28. Schittenhelm MM, Kampa KM, Yee KW, Heinrich MC. The FLT3 inhibitor tandutinib (formerly MLN518) has sequence-independent synergistic effects with cytarabine and daunorubicin. Cell Cycle. 2009;8(16):2621-30.

29. Smith BD, Levis M, Beran M, Giles F, Kantarjian H, Berg K, Murphy KM, Dauses T, Allebach J, Small D. Single-agent CEP-701, a novel FLT3 inhibitor shows biologic and clinical activity in patients with relapsed or refractory acute myeloid leukemia. Blood. 2004;103(10):3669-76.

30. Stone RM, Mandrekar SJ, Sanford BL, Laumann K, Geyer S, Bloomfield CD, Thiede C, Prior TW, Dohner K, Marcucci G, Lo-Coco F, Klisovic RB, Wei A, Sierra J, Sanz MA, Brandwein JM, de Witte T, Niederwieser D, Appelbaum FR, Medeiros BC, Tallman MS, Krauter J, Schlenk RF, Ganser A, Serve H, Ehninger G, Amadori S, Larson RA, Dohner H. Midostaurin plus chemotherapy for acute myeloid leukemia with a FLT3 mutation. N Engl J Med. 2017;377(5):454-64.

31. Levis M. Midostaurin approved for FLT3-mutated AML. Blood. 2017;129(26):3403-6

32. Perl AE, Altman JK, Cortes J, Smith C, Litzow M, Baer MR, Claxton D, Erba HP, Gill S, Goldberg S, Jurcic JG, Larson RA, Liu C, Ritchie E, Schiller G, Spira Al, Strickland SA, Tibes R, Ustun C, Wang ES, Stuart R, Rollig C, Neubauer A, Martinelli G, Bahceci E, Levis M. Selective inhibition of FLT3 by gilteritinib in relapsed or refractory acute myeloid leukaemia: a multicentre, first-inhuman, open-label, phase 1-2 study. Lancet Oncol. 2017;18(8):1061-75.

33. Usuki K, Sakura T, Kobayashi Y, Miyamoto T, lida H, Morita S, Bahceci E, Kaneko M, Kusano M, Yamada S, Takeshita S, Miyawaki S, Naoe T. Clinical profile of gilteritinib in Japanese patients with relapsed/refractory acute myeloid leukemia: an open-label phase 1 study. Cancer Sci. 2018;109(10):3235-44.

34. Perl AE, Martinelli G, Cortes JE, Neubauer A, Berman E, Paolini S, Montesinos P, Baer MR, Larson RA, Ustun C, Fabbiano F, Stasi AD, Stuart R, Olin R, Kasner M, Ciceri F, Chou W-C, Podoltsev N, Recher C, Yokoyama H, Hosono N, Yoon S-S, Lee J-H, Pardee T, Fathi AT, Liu C, Liu X, Bahceci E, Levis MJ. Abstract CT184: Gilteritinib significantly prolongs overall survival in patients with FLT3 mutated (Flt3mut+) relapsed/refractory (R/R) acute myeloid leukemia (AML): Results from the Phase III ADMIRAL trial. Cancer Research. 2019;79(13 Supplement):CT184.

35. Short NJ, Kantarjian H, Ravandi F, Daver N. Emerging treatment paradigms with FLT3 inhibitors in acute myeloid leukemia. Ther Adv Hematol. 2019;10:2040620719827310

36. Li Y, Xu Q, Lv N, Wang L, Zhao H, Wang X, Guo J, Chen C, Li Y, Yu L. Clinical implications of genome-wide DNA methylation studies in acute myeloid leukemia. J Hematol Oncol. 2017;10(1):41.

37. Capone S, Colombo AR, Johnson BK, Triche TJ, Ramsingh G. Methylome of human senescent hematopoietic progenitors. Exp Hematol Oncol. 2018;7(1):32

38. Gan L, Yang Y, Li Q, Feng Y, Liu T, Guo W. Epigenetic regulation of cancer progression by $\mathrm{EZH} 2$ : from biological insights to therapeutic potential. Biomarker Res. 2018;6(1):10.

39. Li T, Zhang C, Hassan S, Liu X, Song F, Chen K, Zhang W, Yang J. Histone deacetylase 6 in cancer. J Hematol Oncol. 2018;11(1):111.

40. Tremblay-LeMay R, Rastgoo N, Pourabdollah M, Chang H. EZH2 as a therapeutic target for multiple myeloma and other haematological malignancies. Biomarker Res. 2018;6(1):34.

41. Andreani G, Dragani M, Serra A, Nicoli P, De Gobbi M, Cilloni D. Venetoclax plus decitabine induced complete remission with molecular response in acute myeloid leukemia relapsed after hematopoietic stem cell transplantation. Am J Hematol. 2019:94(2):E48-50.

42. Das M. Venetoclax with decitabine or azacitidine for AML. Lancet Oncol. 2018;19(12):e672.

43. DiNardo CD, Pratz K, Pullarkat V, Jonas BA, Arellano M, Becker PS, Frankfurt O, Konopleva M, Wei AH, Kantarjian HM, Xu T, Hong WJ, Chyla B, Potluri J, Pollyea DA, Letai A. Venetoclax combined with decitabine or azacitidine in treatment-naive, elderly patients with acute myeloid leukemia. Blood. 2019;133(1):7-17.

44. Rahmat LT, Nguyen A, Abdulhaq H, Prakash S, Logan AC, Mannis GN. Venetoclax in combination with Decitabine for relapsed T-cell acute lymphoblastic leukemia after allogeneic hematopoietic cell transplant. Case Rep Hematol. 2018;2018:6092646.
45. DiNardo CD, Pratz KW, Letai A, Jonas BA, Wei AH, Thirman M, Arellano M, Frattini MG, Kantarjian H, Popovic R, Chyla B, Xu T, Dunbar M, Agarwal SK, Humerickhouse R, Mabry M, Potluri J, Konopleva M, Pollyea DA. Safety and preliminary efficacy of venetoclax with decitabine or azacitidine in elderly patients with previously untreated acute myeloid leukaemia: a nonrandomised, open-label, phase 1b study. Lancet Oncol. 2018;19(2):216-28.

46. Liu B, Narurkar R, Hanmantgad M, Zafar W, Song Y, Liu D. Venetoclax and low-dose cytarabine induced complete remission in a patient with high-risk acute myeloid leukemia: a case report. Front Med. 2018;12(5):593-9.

47. Esteve J, Schots R, Bernal Del Castillo T, Lee J-H, Wang ES, Dinner S, Minden MD, Salamero O, Sierra J, Yoshimoto G, Laribi K, Halka J, Montesinos P, Liu S, Rich ES, Bahceci E. Multicenter, open-label, 3-arm study of Gilteritinib, Gilteritinib plus Azacitidine, or Azacitidine alone in newly diagnosed FLT3 mutated (FLT3 Mut+) acute myeloid leukemia (AML) patients ineligible for intensive induction chemotherapy: findings from the safety cohort. Blood. 2018;132(Suppl 1):2736.

48. Ossenkoppele G, Löwenberg B. How I treat the older patient with acute myeloid leukemia. Blood. 2015;125(5):767-74.

49. Pratz KW, Cherry M, Altman JK, Cooper B, Cruz JC, Jurcic JG, Levis MJ, Lin TL, Perl AE, Podoltsev NA, Schiller GJ, Liu C, Bahceci E. Updated results from a phase 1 study of Gilteritinib in combination with induction and consolidation chemotherapy in subjects with newly diagnosed acute myeloid leukemia (AML). Blood. 2018;132(Suppl 1):564.

50. Stone RM, Manley PW, Larson RA, Capdeville R. Midostaurin: its odyssey from discovery to approval for treating acute myeloid leukemia and advanced systemic mastocytosis. Blood Adv. 2018;2(4):444-53.

51. Walker AR, Wang H, Walsh K, Bhatnagar B, Vasu S, Garzon R, Canning R, Geyer S, Wu YZ, Devine SM, Klisovic R, Blum W, Marcucci G. Midostaurin, bortezomib and MEC in relapsed/refractory acute myeloid leukemia. Leuk Lymphoma. 2016;57(9):2100-8.

52. Kampa-Schittenhelm KM, Frey J, Haeusser LA, Illing B, Pavlovsky AA Blumenstock G, Schittenhelm MM. Crenolanib is a type I tyrosine kinase inhibitor that inhibits mutant KIT D816 isoforms prevalent in systemic mastocytosis and core binding factor leukemia. Oncotarget. 2017;8(47): 82897-909.

53. Zimmerman El, Turner DC, Buaboonnam J, Hu S, Orwick S, Roberts MS, Janke LJ, Ramachandran A, Stewart CF, Inaba H, Baker SD. Crenolanib is active against models of drug-resistant FLT3-ITD-positive acute myeloid leukemia. Blood. 2013;122(22):3607-15.

54. Iyer SP, Jethava Y, Karanes C, Eckardt JR, Collins R. Safety study of salvage chemotherapy high-dose Ara-C/Mitoxantrone (HAM) and type I FLT3-TKI Crenolanib in first relapsed/primary refractory AML. Blood. 2016;128(22):3983.

55. Elshoury A, Przespolewski A, Baron J, Wang ES. Advancing treatment of acute myeloid leukemia: the future of FLT3 inhibitors. Expert Rev Anticancer Ther. 2019;19(3):273-86

56. Wang ES. Incorporating FLT3 inhibitors in the frontline treatment of FLT3 mutant acute myeloid leukemia. Best Pract Res Clin Haematol. 2019;32(2):154-62

57. Wang ES, O'Dwyer K. High dose daunorubicin: new standard of care for FLT3 ITD mutant AML. Leuk Res. 2018:69:87-8.

58. Weis TM, Marini BL, Bixby DL, Perissinotti AJ. Clinical considerations for the use of FLT3 inhibitors in acute myeloid leukemia. Crit Rev Oncol Hematol. 2019;141:125-38.

59. Tallman MS, Wang ES, Altman JK, Appelbaum FR, Bhatt VR, Bixby D, Coutre SE, De Lima M, Fathi AT, Fiorella M, Foran JM, Hall AC, Jacoby M, Lancet J, LeBlanc TW, Mannis G, Marcucci G, Martin MG, Mims A, O'Donnell MR, Olin R, Peker D, Perl A, Pollyea DA, Pratz K, Prebet T, Ravandi F, Shami PJ, Stone RM, Strickland SA, et al. Acute myeloid leukemia, version 3.2019, NCCN clinical practice guidelines in oncology. J Natl Compr Cancer Netw. 2019:17(6):721-49.

60. Pratz KW, Levis M. How I treat FLT3-mutated AML. Blood. 2017;129(5):565-71.

\section{Publisher's Note}

Springer Nature remains neutral with regard to jurisdictional claims in published maps and institutional affiliations. 